\title{
Short communication: Insulin responsiveness is affected by the level of milk replacer offered to young calves
}

\author{
A. Bach, ${ }^{*} \dagger^{1}$ L. Domingo, $\dagger$ C. Montoro, $\dagger$ and M. Terré $†$ \\ *Institució Catalana de Recerca i Estudis Avançats, 08010 Barcelona, Spain \\ †Department of Ruminant Production, Institut de Recerca i Tecnologia Agroalimentàries, 08140 Caldes de Montbui, Spain
}

\begin{abstract}
Eight male Holstein calves $(40.6 \pm 2.9 \mathrm{~kg}$ of BW and $7.8 \pm 1.6 \mathrm{~d}$ of age) were individually housed and allocated to either a low milk replacer (MR) allowance of 2 daily doses of $2 \mathrm{~L}$ each $(478.5 \mathrm{~g} / \mathrm{d}$ of dry matter from MR), or to a high allowance of 2 daily allotments of $4 \mathrm{~L}(957.0 \mathrm{~g} / \mathrm{d}$ of dry matter from MR). In addition all calves had ad libitum access to the same starter feed and water. At d 7, 30, and 60 of experiment all calves were submitted to a glucose tolerance test (GTT) that consisted on an i.v. infusion of $180 \mathrm{mg} / \mathrm{kg}$ of $\mathrm{BW}$ of glucose at $4 \mathrm{~h}$ after the morning MR feeding. Blood was harvested at $-15,-5,0,4,8,12,18,25,35,45$, and 60 min relative to glucose infusions. Blood samples collected at $-15,-5$, and 0 relative to glucose infusion were used as baseline concentrations of glucose and insulin. Then, the area under the curve (concentration/min) for glucose and insulin was calculated as the increase with respect to the baseline. Next, the clearance rates of insulin $(\% / \mathrm{min})$, glucose $(\% / \mathrm{min})$, as well as insulin sensitivity were computed. The increase in blood glucose following the GTT (assessed as area under the curve) was similar in both low and high calves, which indicates that all animals were able to control glycemia effectively. Similarly, clearance rates of glucose and insulin were not different between low and high calves. However, calves in the high group needed a substantially greater serum insulin concentration (98.7 $\pm 13.2 \mu \mathrm{U} / \mathrm{mL})$ than low calves $(41.5 \pm 13.2 \mu \mathrm{U} / \mathrm{mL})$ to control glycemia. Furthermore, as age increased, the rise in serum insulin elicited by the GTT continued to increase in high but not in low calves. Insulin to glucose ratio was greater in high $(157.5 \pm 7.8 \mu \mathrm{U} / \mathrm{mg})$ than in low $(46.7 \pm 7.8 \mu \mathrm{U} / \mathrm{mg})$ calves. This ratio increased with age and in a more pronounced fashion in high than in low calves and the same pattern was observed for insulin sensitivity. We concluded that offering $8 \mathrm{~L}$ of $\mathrm{MR} / \mathrm{d}$ in 2 separate meals decreases insulin sensitivity
\end{abstract}

Received September 25, 2012.

Accepted March 18, 2013.

${ }^{1}$ Corresponding author: alex.bach@irta.cat of young calves. Further research is needed to assess whether the impaired glucose responsiveness of calves can be minimized by feeding milk more frequently.

Key words: calf, glucose, metabolism, plane of nutrition

\section{Short Communication}

In recent years, accelerated calf programs offering relatively large volumes of milk have been increasingly implemented in the field. However, in most settings, calves are fed large volumes of milk distributed in 2 daily feedings, which is in contrast to what would naturally occur. Calves allowed to suckle their dams consume milk about 8 to 12 times daily in bouts of about 10 min (Reinhardt and Reinhardt, 1981), consume approximately $6 \mathrm{~kg} / \mathrm{d}$ during the first week of life, and reach a maximum of $12 \mathrm{~kg} / \mathrm{d}$ at 9 wk of life (de Passillé et al., 2008). The Holstein calf seems to be more prone to insulin resistance than other breeds (Bossaert et al., 2009), and insulin resistance is a problem in veal calves that receive large volumes of milk (Hostettler-Allen et al., 1994). Providing large amounts of milk twice daily (i.e., 3 or $4 \mathrm{~L}$ twice daily) may induce a rise in glucose that may have consequences for future metabolic responses. For instance, plasma glucose concentrations in veal calves fed 6 times a day are less than in those fed equivalent amounts of milk twice daily (Kaufhold et al., 2000). Furthermore, Terré et al. (2009) reported that calves receiving large amounts of milk twice daily had an increased insulin to glucose ratio, indicative of a certain degree of insulin resistance as compared with those also receiving $4 \mathrm{~L} / \mathrm{d}$ twice daily.

The objective of the current study was to compare glucose metabolism and insulin sensitivity in calves offered either 2 or $4 \mathrm{~L}$ of the same milk replacer (MR) twice daily. Eight male Holstein calves $(40.6 \pm 2.9 \mathrm{~kg}$ of BW and $7.8 \pm 1.6 \mathrm{~d}$ of age) were purchased from commercial farms and brought to the research facilities of Institut de Recerca i Tecnologia Agroalimentàries (El Prat, Barcelona, Spain). Upon arrival, all calves received $2 \mathrm{~L}$ of MR $(25 \% \mathrm{CP}$ and $19.2 \%$ fat; Sprayfo Excellent 60, Sloten BV, Deventer, the Netherlands) 
at an $11 \%$ dilution rate. The next day, and for the following $10 \mathrm{~d}$, all calves received $2 \mathrm{~L}$ of $\mathrm{MR}$ at a $12.5 \%$ dilution rate twice daily at 0700 and $1900 \mathrm{~h}$. At that time, calves were randomly allocated to either a low ration $(\mathbf{L R})$ of 2 daily feedings $(478.5 \mathrm{~g} / \mathrm{d}$ of $\mathrm{DM}$ from $\mathrm{MR}$ ) of $2 \mathrm{~L}$ of $\mathrm{MR}$ or a high ration (HR) of 2 daily feedings $(957.0 \mathrm{~g} / \mathrm{d}$ of $\mathrm{DM}$ from MR) of $4 \mathrm{~L}$ of $\mathrm{MR}$. Calves had ad libitum access to a starter feed (19.5\% CP, $17.7 \% \mathrm{NDF}, 2.9$ Mcal of ME/kg, DM basis) and water throughout the experiment and were housed in individual pens $(1 \times 1.55 \mathrm{~m})$ bedded with sawdust on a daily basis. All procedures were approved and monitored by the Animal Care Committee of Institut de Recerca i Tecnologia Agroalimentàries.

At d 7, 30, and 60 of the experiment and $4 \mathrm{~h}$ after the morning offer of MR, when plasma glucose and serum insulin concentrations were expected to be close to basal levels (Kamalu and Trenkle, 1978), all calves were submitted to a glucose tolerance test (GTT) that consisted of an i.v. infusion of $180 \mathrm{mg} / \mathrm{kg}$ of BW of glucose. Calves were fed at 0700 and $0900 \mathrm{~h}$ and an indwelling catheter (Abbocath-T 16 gauge $\times 140 \mathrm{~mm}$; Hospira Inc., Lake Forest, IL) was placed in the left jugular vein. The catheter was used to infuse glucose $(500 \mathrm{~g} / \mathrm{L}$ of glucose anhydrous; B. Braun Medical, Terrassa, Spain) and to collect blood samples. Blood was harvested into in 4-mL evacuated tubes containing a glycolysis inhibitor (BD Vacutainer fluoride tubes, Becton Dickinson, Madrid, Spain) to determine plasma glucose concentrations, and 5-mL evacuated tubes containing EDTA (BD Vacutainer serum tubes) for serum insulin determinations. Blood samples were obtained at $-15,-5,0,4,8,12,18,25,35,45$, and 60 min relative to glucose infusions. Catheter patency was maintained by flushing with $5 \mathrm{~mL}$ of heparinized saline solution (1,000 USP units of heparin/mL). All blood samples were immediately placed on ice for at least $20 \mathrm{~min}$, centrifuged at $1,500 \times \mathrm{g}$ at $4^{\circ} \mathrm{C}$ for $15 \mathrm{~min}$, and plasma and serum were decanted and stored at $-20^{\circ} \mathrm{C}$ until subsequent analysis. Serum glucose concentrations were assayed using a glucose RTU kit (bioMerieux S.A., Marcy l'Etoile, France). Serum insulin determinations were conducted using determined using ELISA (kit 10-1131-01, Mercodia, Uppsala, Sweden).

Blood samples collected at $-15,-5$, and 0 min relative to glucose infusion were used to determine baseline concentrations of glucose and insulin. Then, the area under the curve (concentration/min) for these 2 metabolites was calculated as the increase with respect to the baseline using the trapezoidal method. Next, the clearance rates of insulin $(\% / \mathrm{min} ; \mathrm{CRI})$ and glucose (\%/min; CRG) were computed following Pires et al. (2007):
$\mathrm{CRI}=\{[\log (\mathrm{PI})-\log (\mathrm{NI})] /(\mathrm{TTP}-\mathrm{TTN})\} \times 100$ and

$\mathrm{CRG}=\{[\log (\mathrm{PG})-\log (\mathrm{NG})] /(\mathrm{TTP}-\mathrm{TTN})\} \times 100$,

where PI is peak serum insulin concentrations; NI is nadir serum insulin concentrations; $\mathrm{PG}$ is peak serum glucose concentrations; NG is nadir serum glucose concentrations; TTP is time to peak (for each insulin and glucose); and TTN is time to nadir. Furthermore, insulin sensitivity was estimated using a simplified alternative to the minimal model (Bergman, 1989) following Christoffersen et al. (2009).

Data were analyzed using a mixed-effects model that accounted for the fixed effects of level of MR (4 or 8 $\mathrm{L} / \mathrm{d}$ ), time of $\operatorname{GTT}(7,3$, or $60 \mathrm{~d})$, and their interaction, plus the random effect of calf within treatment. Time of GTT entered the model as a repeated measure using a compound symmetry variance-covariance structure (which yielded the smallest Bayesian information criterion values). Differences were declared significant when $P<0.05$ and tendencies when $P \leq 0.10$.

The increase in blood glucose following the GTT (assessed as area under the curve) was similar in calves receiving both LR and HR (Table 1), which indicates that animals in all cases were able to control glycemia effectively. However, HR calves needed a substantially greater $(P<0.001)$ serum insulin concentration to control glycemia than LR calves (Table 1). Furthermore, as age increased, the rise in serum insulin elicited by the GTT continued to increase $(P=0.01)$ in HR calves but not in LR calves (Figure 1). The maximum insulin concentration (above the baseline) was greater in HR calves than LR calves, it progressively increased with age, and it tended $(P=0.08)$ to increase more in HR calves than LR calves (Table 1). Maximum serum glucose levels did not differ between treatments, but increased $(P<0.05)$ with age, and the increase was more $(P<0.05)$ marked in HR calves than LR calves (Table 1). Hugi et al. (1998) also reported increases in insulin resistance in veal calves fed large volumes of a MR containing about $40 \%$ lactose twice daily. Furthermore, as time of exposure to MR increased, insulin sensitivity progressively declined and this decline tended $(P$ $=0.05$ ) to be more pronounced in $\mathrm{HR}$ calves (from $3.14 \pm 0.67$ to $0.64 \pm 0.12 \mathrm{~mL} / \mathrm{min} \times \mu \mathrm{U} / \mathrm{mL}$ per $\mathrm{kg}$ of $\mathrm{BW}$ ) than in LR calves (from $3.27 \pm 0.67$ to $0.64 \pm$ $0.12 \mathrm{~mL} / \mathrm{min} \times \mu \mathrm{U} / \mathrm{mL}$ per $\mathrm{kg}$ of $\mathrm{BW})$. In other words, HR calves tended to produce more insulin to maintain similar glycemic levels than those found in LR calves.

Neither the clearance rate of glucose or insulin nor time to reach baseline concentrations differed between treatments (Table 1). Therefore, it would seem that the tendency toward a decrease in insulin sensitivity 
Table 1. Effect of plane of nutrition (4 vs. $8 \mathrm{~L}$ of milk replacer per day) on glucose and insulin responses to an i.v. glucose tolerance test

\begin{tabular}{|c|c|c|c|c|c|c|}
\hline Item & \multicolumn{2}{|c|}{ Amount of milk replacer } & $\mathrm{SE}$ & \multicolumn{3}{|c|}{$P$-value ${ }^{1}$} \\
\hline Glucose $\mathrm{AUC},{ }^{2} \mathrm{mg} / \mathrm{dL} \times 60 \mathrm{~min}$ & 1,681 & 1,677 & 142.0 & 0.62 & 0.91 & 0.84 \\
\hline Maximum glucose increase, $\mathrm{mg} / \mathrm{dL}$ & 86.6 & 97.5 & 4.98 & 0.17 & 0.05 & 0.02 \\
\hline Maximum insulin increase, $\mu \mathrm{U} / \mathrm{mL}$ & 41.5 & 98.7 & 13.17 & 0.02 & 0.02 & 0.08 \\
\hline Clearance rate of glucose, $\% / \mathrm{min}$ & 8.85 & 8.6 & 1.61 & 0.90 & 0.57 & 0.40 \\
\hline Time to insulin baseline, $\min$ & 24.4 & 27.2 & 3.84 & 0.63 & 0.85 & 0.32 \\
\hline Insulin to glucose, $\mu \mathrm{U} / \mathrm{mg}$ & 46.7 & 157.5 & 7.81 & $<0.001$ & 0.006 & 0.03 \\
\hline Insulin sensitivity, ${ }^{3} \mathrm{~mL} / \mathrm{min} \times \mu \mathrm{U} / \mathrm{mL}$ per $\mathrm{kg}$ of $\mathrm{BW}$ & 1.89 & 1.24 & 0.25 & 0.08 & $<0.001$ & 0.05 \\
\hline
\end{tabular}

${ }^{1} \mathrm{~T}=$ effect of treatment; $\mathrm{A}=$ effect of age of measurement; $\mathrm{T} \times \mathrm{A}=$ interaction between the effect of treatment and age.

${ }^{2} \mathrm{AUC}=$ area under the curve (discounting baseline concentration).

${ }^{3}$ Calculated according to Christoffersen et al. (2009).

due to high volumes of MR being fed twice daily was compensated by an increase in insulin production. In fact, the insulin to glucose ratio was 3 -fold greater $(P$ $<0.001)$ in HR calves compared with LR calves. The ratio increased with age more $(P<0.05)$ markedly in HR calves than in LR calves (Table 1), which would reinforce the observation that as calves were becoming older, those receiving large volumes of MR became increasingly resistant to insulin.

As expected, calves consuming $8 \mathrm{~L}$ of $\mathrm{MR} / \mathrm{d}$ gained more BW $(16.1 \pm 2.42 \mathrm{~kg})$ than those on $6 \mathrm{~L}$ of $\mathrm{MR} / \mathrm{d}$ $(8.45 \pm 2.42 \mathrm{~kg})$ during the study. Interestingly, though, calves on $8 \mathrm{~L}$ of $\mathrm{MR} / \mathrm{d}$ showed a decreasing $(P<0.05)$

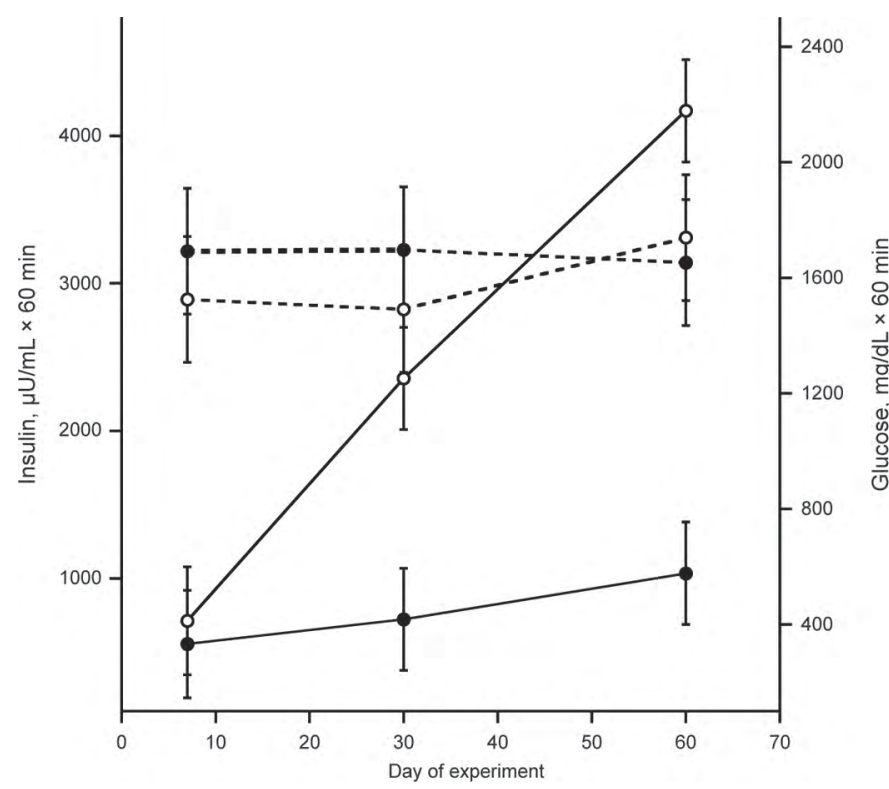

Figure 1. Evolution of area under the curve of blood insulin (solid line) and glucose (dashed line) concentrations as affected by plane of nutrition ( 4 vs. $8 \mathrm{~L} / \mathrm{d}$ of milk replacer). Closed circles represent calves on $4 \mathrm{~L}$ of milk replacer per day, open circles calves on $8 \mathrm{~L}$ of milk replacer per day. rate of gain along the first, fourth, and final week of study $(928,765$, and $645 \pm 95.5 \mathrm{~g} / \mathrm{d}$, respectively), whereas calves on $6 \mathrm{~L}$ of MR/d progressively increased $(P<0.05)$ the rate of gain during the same weeks $(438$, 493 , and $575 \mathrm{~g} / \mathrm{d}$, respectively). A decrease in insulin sensitivity has been previously linked with an increase in fat deposition (Palmquist et al., 1992; van den Borne et al., 2007) mainly from FA (not from carbohydrates). Thus, it could be speculated that calves consuming $8 \mathrm{~L}$ of $\mathrm{MR} / \mathrm{d}$ in 2 allotments had an increased fat deposition, and, accordingly, their growth rate decreased as they become older and continued to consume MR as a consequence of a progressive decrease in insulin sensitivity and potentially increased adiposity.

Furthermore, after calving, dairy cows are faced with a metabolic status marked by a negative energy balance (NRC, 2001) and insulin sensitivity during early lactation is relatively low (Kerestes et al., 2009). Both reduced serum insulin concentrations or impaired insulin sensitivity exacerbate lipid mobilization during early lactation and increase plasma NEFA concentrations and, thus, the risk of ketosis (Hayirli, 2006). Whether metabolic changes early in life may exert long-term effects on the metabolic function of calves is unknown, but several reports link the plane of nutrition and growth early in life with future animal performance (Bach, 2012; Soberon et al., 2012). If the impaired insulin responsiveness observed in calves fed large amounts of milk twice daily was sustained over time, enhanced growth-feeding programs should require increased milkfeeding frequencies. More research is needed to assess whether the impaired glucose responsiveness of calves fed large volumes of milk twice daily are long lasting.

\section{REFERENCES}

Bach, A. 2012. Ruminant Nutrition Symposium: Optimizing Performance of the Offspring: Nourishing and managing the dam and 
postnatal calf for optimal lactation, reproduction, and immunity. J. Anim. Sci. 90:1835-1845.

Bergman, R. N. 1989. Lilly lecture 1989. Toward physiological understanding of glucose tolerance. Minimal-model approach. Diabetes 38:1512-1527.

Bossaert, P., J. L. M. R. Leroy, S. De Campeneere, S. De Vliegher, and G. Opsomer. 2009. Differences in the glucose-induced insulin response and the peripheral insulin responsiveness between neonatal calves of the Belgian Blue, Holstein-Friesian, and East Flemish breeds. J. Dairy Sci. 92:4404-4411.

Christoffersen, B., U. Ribel, K. Raun, V. Golozoubova, and G. Pacini. 2009. Evaluation of different methods for assessment of insulin sensitivity in Gottingen minipigs: Introduction of a new, simpler method. Am. J. Physiol. Regul. Integr. Comp. Physiol. 297:R1195-R1201.

de Passillé, A. M., P. G. Marnet, H. Lapierre, and J. Rushen. 2008. Effects of twice-daily nursing on milk ejection and milk yield during nursing and milking in dairy cows. J. Dairy Sci. 91:1416-1422.

Hayirli, A. 2006. The role of exogenous insulin in the complex of hepatic lipidosis and ketosis associated with insulin resistance phenomenon in postpartum dairy cattle. Vet. Res. Commun. 30:749-774.

Hostettler-Allen, R. L., L. Tappy, and J. W. Blum. 1994. Insulin resistance, hyperglycemia, and glucosuria in intensively milk-fed calves. J. Anim. Sci. 72:160-173.

Hugi, D., L. Tappy, H. Sauerwein, R. M. Bruckmaier, and J. W. Blum. 1998. Insulin-dependent glucose utilization in intensively milk-fed veal calves is modulated by supplemental lactose in an age-dependent manner. J. Nutr. 128:1023-1030.

Kamalu, T. N., and A. H. Trenkle. 1978. Postprandial changes in plasma insulin, plasma glucose, and plasma free fatty acids of milk-fed calves. Nutr. Rep. Int. 18:243-248.
Kaufhold, J. N., H. M. Hammon, R. M. Bruckmaier, B. H. Breier, and J. W. Blum. 2000. Postprandial metabolism and endocrine status in veal calves fed at different frequencies. J. Dairy Sci. $83: 2480-2490$.

Kerestes, M., V. Faigl, M. Kulcsár, O. Balogh, J. Földi, H. Fébel, Y. Chilliard, and G. Huszenicza. 2009. Periparturient insulin secretion and whole-body insulin responsiveness in dairy cows showing various forms of ketone pattern with or without puerperal metritis. Domest. Anim. Endocrinol. 37:250-261.

NRC. 2001. Nutrient Requirements of Dairy Cattle. 7th rev. ed. Natl. Acad. Sci., Washington, DC.

Palmquist, D. L., J. Doppenberg, K. L. Roehrig, and D. J. Kinsey. 1992. Glucose and insulin metabolism in ruminating and veal calves fed high and low fat diets. Domest. Anim. Endocrinol. 9:233-241.

Pires, J. A. A., A. H. Souza, and R. R. Grummer. 2007. Induction of hyperlipidemia by intravenous infusion of tallow emulsion causes insulin resistance in Holstein cows. J. Dairy Sci. 90:2735-2744.

Reinhardt, V., and A. Reinhardt. 1981. Cohesive relationships in a cattle herd. Behaviour 77:121-151.

Soberon, F., E. Raffrenato, R. W. Everett, and M. E. Van Amburgh. 2012. Preweaning milk replacer intake and effects on long-term productivity of dairy calves. J. Dairy Sci. 95:783-793.

Terré, M., C. Tejero, and A. Bach. 2009. Long-term effects on heifer performance of an enhanced-growth feeding programme applied during the preweaning period. J. Dairy Res. 76:331-339.

van den Borne, J. J. G. C., G. E. Lobley, M. W. A. Verstegen, J. M. Muijlaert, S. J. J. Alferink, and W. J. J. Gerrits. 2007. Body fat deposition does not originate from carbohydrates in milk-fed calves. J. Nutr. 137:2234-2241. 